Original Article

\title{
Dentistry by Volition or by Happenstance-A Questionnaire Study
}

\section{R.J. Shobana Priya ${ }^{1}$, R. Palanivel Pandian², Sangeeta Chavan ${ }^{3}$, K.S. Premkumar ${ }^{4}$, S. Shrimathi ${ }^{5}$, K. Umesh ${ }^{6}$}

\begin{abstract}
Introduction: The present study contemplates about the profile of first year dental students and their attitudes towards choosing dentistry as a career.
\end{abstract}

Aim and objectives : To assess the factors that leads to the choice of dentistry as an occupation among the first year students in one of the private dental colleges in Madurai, Tamil Nadu, India.

Materials and methods: The study sample includes first year students in one of the private dental colleges in Madurai, who were enrolled during the academic year of 2017-2018. A cross sectional survey was conducted among 75 students of first year BDS using a self-administered questionnaire. The survey form consisted of ten close ended questions. Information was collected, evaluated and delineated as numeral and percentage.

Results: The response rate of the study participants was $100 \%$. Majority of the participants $58.7 \%$ of them have chosen dentistry because they were unable to get an admission in medical course.

Discussion: Majority of the students in the study have chosen dentistry as an alternative to medicine and few of them by their family impact.

Key-words: Dental education, profession, chance, dentistry, post graduation.

\section{Introduction}

During childhood, each children have their own dreams about their profession, it may be either doctor, engineer, teacher, etc as days passes this imagination dissipates either due to internal or external factors and they are pushed into a situation to deviate from their dream either by their own interest or by others compulsion. Career is an individual's metaphorical journey through learning, work and other aspects of life. ${ }^{1}$ The working condition, financial situation, status, security and interest of the individual play an important role in deciding a career. ${ }^{2}$ The choice of dentistry as a career is a ingenious decision and it is considered passionate which has a great impact on the future. ${ }^{3}$ Dental education is the institution where the students are sculptured to sculpt the smile of other. ${ }^{4}$ The students entering the dental education can be divided into three categories, Dentistry by choice - where dentistry is their passion, Dentistry by chance and where they pick up the profession under compulsion. ${ }^{5}$ Dentistry is a branch of medicine that consists of the evaluation, diagnosis, prevention, and treatment of diseases, disorders, and conditions of the oral cavity, maxillofacial area and the adjacent and associated structures and their impact on the human body. The scope of dental education is based on training and experience which also has an impact on professional ethics and applicable law. ${ }^{6}$ A study carried out based on the attitude of the dental students reveals that one of the obtained elements of an individual is attitude, initiating and sustaining proper attitudes by dental students have effect on the standard of curative care delivered to the patients. ${ }^{7}$ The duration of undergraduate training for Bachelor of Dental Surgery (BDS) in India is 4years and 1year of compulsory rotatory internship as prescribed by the Dental Council of India, the regulatory body of dental education. The aim of our study was to assess the factors that led to the choice of dentistry as an occupation among the first year dental students in one of the private dental colleges in Madurai, Tamil Nadu.

\section{Methodology}

A descriptive cross sectional survey was conducted among 75 students in one of the private dental colleges in Madurai, over a period of 1 month from June $23^{\text {rd }}$ to July $23^{\text {rd }} 2018$. Ethical approval was obtained from institutional review committee. Students were informed about the survey; informed consent was obtained from all the students before the start of the study. A self administered structured questionnaire was prepared in English language. The survey form consisted of ten close ended questions was used to collect the data based on the previous studies conducted by AL-Bitar et al, Hallisey et al, Bernable et al, with some additions related to surrounding influences. ${ }^{2,8,9}$ The study was carried out in the first year lecture hall and 
the questionnaire was distributed to the participants by two investigators. All the participants were given 20 minutes time to fill the questionnaire in the college first year lecture hall and retrieved immediately. It was made clear to the students that their identity would not be disclosed to avoid the social desirability bias. The time limit set for collection of data was for a period of 2 days in the month of June, 2018. The survey questionnaire includes items related to choosing dentistry, their alternative choice of interest, reasons to choose dentistry and their mentality towards serving rural or urban sectors. The content validity of the questionnaire was evaluated by the experts. A pilot study was conducted to check the feasibility of the questionnaire and it was conducted among 10 students in one of the private dental colleges, Madurai, Tamil Nadu. Based on the interpretation of the pilot study, necessary modifications were made in the questionnaire and cross sectional survey were conducted among 75 students. The data were entered into Microsoft excel and statistical package for social sciences (IBM SPSS statistics for windows version 20) was used.

\section{Results}

The study was done to assess the reason for choosing dentistry as a career choice, among the total study group of 75 students out of which 60 were females and 15 were male students from the first year BDS. The gender distribution of the study participants is shown in the bar graph no: 1. Majority of the students who got into dentistry by chance as a professional career was $58.7 \%$. Nearly half of the participants $58.7 \%$ of them choose dentistry because they were unable to get an admission in medical course, $28 \%$ of them choose dentistry out of interest, $13.3 \%$ of them were due to their family influence and the alternative choice of interest for $68 \%$ of the students was medicine, other than dentistry. About $77.3 \%$ of the students felt that dentistry is not related to aesthetics alone. Nearly $38.7 \%$ of the students felt that dentistry could help them to serve people by providing good oral health services, only $10.7 \%$ of them felt that it would

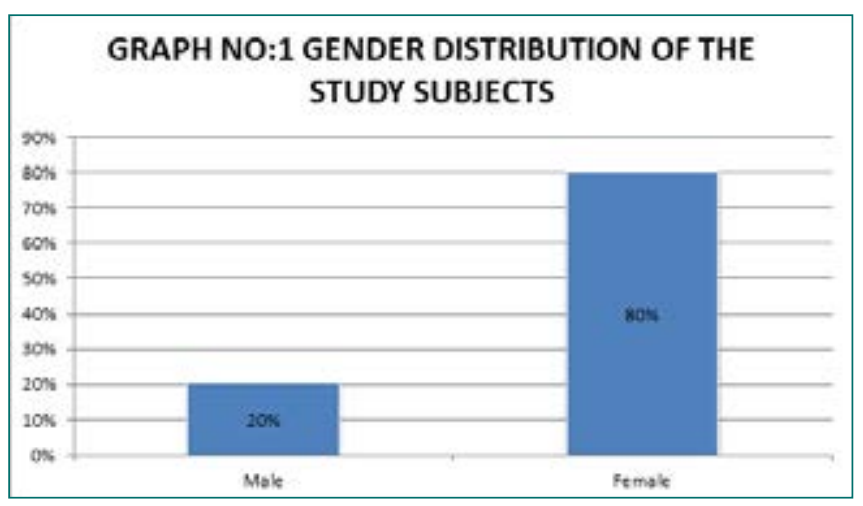

help earning for their livelihood and $24 \%$ of them felt that dentistry was a prestigious career. Majority of the students $42.7 \%$ were aware that dentistry is not only confined to dental treatment of tooth problems and improving aesthetics but also the surgical correction of maxillofacial anomalies. Nearly half of the study participants $55.3 \%$ of them would like to serve the rural population. After completion of their undergraduate course in dentistry, $64 \%$ of the students were interested in postgradution and $25.3 \%$ of the study participants have a dream to establish their own clinical practice. The gender wise responses to the question asked are described in Table 1.

\section{Discussion}

The purpose of the present study was to obtain information about the reasons for choosing dentistry as a career either by choice or chance, among the first year students in one of the private dental colleges in Madurai. The students can obtain admittance into a dental institution through the National Eligibility cum Entrance examination (NEETUG) is an examination in all over the India conducted by Central Broad of Secondary Education. The present study confessed that choosing dentistry as a career has a certain reasons nearly half of the study participants $(58.7 \%)$ got dentistry by chance, because they have chosen dentistry as an alternative to medicine and remaining few of them choose this branch out of interest, similar results were obtained in the study conducted by Ashish et al where most of the dental students(78\%)of them chose dentistry as an alternative to medicine. ${ }^{10}$ This might be due to the common perception of the vicinity that medical students relish highly honoured social status than dentistry. ${ }^{11}$ This was dissimilar to the study conducted by Augiar et al where $(67.8 \%)$ most of the students felt that dentistry to be superior status in the professional career and for one's own accomplishment. ${ }^{12}$ In the present study only a few $25.3 \%$ of them were interested to establish their own clinical practice because the value of investment for clinical setting is very high when compared to their return earnings in India. This result was in contrast to the study conducted by Jonathan et al, where nearly half of the participants(57.4\%) planned to establish clinical practice because in United States, an average dentist in clinical practice works for about 32 hours a week and the income is also very high when compared to India. ${ }^{13} \mathrm{~A}$ study conducted by Brand at al, Sofola et al, where students choose dentistry for clinical practice as a common motive but it was a difficult option for them due to financial pressure and in a way that agrees with the present study. ${ }^{14,15}$ The current study shows that $38.7 \%$ of them felt that they could serve people through dentistry. This result was similar with the study conducted by Singh 
Table 1: Responses of study participants to the questions

\begin{tabular}{|c|c|c|c|}
\hline Questions & Males & Females & Total \\
\hline $\begin{array}{l}\text { 1. You chose dentistry by } \\
\text { Choice } \\
\text { Chance }\end{array}$ & $\begin{array}{l}09[60 \%] \\
06[40 \%]\end{array}$ & $\begin{array}{l}22[36.6 \%] \\
38[63.3 \%]\end{array}$ & $\begin{array}{l}31[41.3 \%] \\
44[58.7 \%]\end{array}$ \\
\hline $\begin{array}{l}\text { 2. What is the reason for choosing dentistry as a career } \\
\text { Unable to get a seat in medicine } \\
\text { Family influence } \\
\text { Interest in dentistry }\end{array}$ & $\begin{array}{l}08[53.3 \%] \\
02[13.3 \%] \\
05[33.3 \%]\end{array}$ & $\begin{array}{r}36[60 \%] \\
08[13.3 \%] \\
16[26.6 \%]\end{array}$ & $\begin{array}{r}44[58.7 \%] \\
10[13.3 \%] \\
21[28 \%]\end{array}$ \\
\hline $\begin{array}{l}\text { 3. Whether dentistry is related to aesthetics only } \\
\text { Yes } \\
\text { No }\end{array}$ & $\begin{array}{l}02[13.3 \%] \\
13[86.6 \%]\end{array}$ & $\begin{array}{l}15[25 \%] \\
45[75 \%]\end{array}$ & $\begin{array}{l}17[27.7 \%] \\
58[77.3 \%]\end{array}$ \\
\hline $\begin{array}{l}\text { 4. Factors influencing in choosing dentistry } \\
\text { Career choice } \\
\text { Self-employment } \\
\text { Family influence }\end{array}$ & $\begin{array}{r}05[33.3 \%] \\
10[66.6 \%] \\
0\end{array}$ & $\begin{array}{l}20[33.3 \%] \\
26[43.3 \%] \\
14[23.3 \%]\end{array}$ & $\begin{array}{r}25[33.3 \%] \\
36[48 \%] \\
14[18.7 \%]\end{array}$ \\
\hline $\begin{array}{l}\text { 5. Dentistry as a profession can } \\
\text { Help people } \\
\text { Help me make money } \\
\text { Prestige } \\
\text { Others }\end{array}$ & $\begin{array}{r}05[33.3 \%] \\
03[20 \%] \\
04[26.6 \%] \\
03[20 \%]\end{array}$ & $\begin{array}{r}24[40 \%] \\
05[8.3 \%] \\
14[23.3 \%] \\
17[28.3 \%]\end{array}$ & $\begin{array}{r}29[38.7 \%] \\
08[10.7 \%] \\
18[24 \%] \\
20[26 \%]\end{array}$ \\
\hline $\begin{array}{l}\text { 6. What is your view about dentistry Confined only to } \\
\text { the treatment of tooth problem } \\
\text { To improve aesthetics } \\
\text { Surgical correction of maxillofacial anomalies } \\
\text { Others }\end{array}$ & $\begin{array}{r}04[26.6 \%] \\
01[6.6 \%] \\
08[53.3 \%] \\
02[13.3 \%]\end{array}$ & $\begin{array}{r}14[23.3 \%] \\
05[8.3 \%] \\
24[40 \%] \\
17[28.3 \%]\end{array}$ & $\begin{array}{r}18[24 \%] \\
06[8 \%] \\
32[42.7 \%] \\
19[25.3 \%]\end{array}$ \\
\hline $\begin{array}{l}\text { 7. Population you like to serve } \\
\text { Rural } \\
\text { Urban } \\
\text { Both }\end{array}$ & $\begin{array}{r}07[46.6 \%] \\
07[46.6 \%] \\
01[6.6 \%]\end{array}$ & $\begin{array}{r}32[53.3 \%] \\
28[46.6 \%] \\
0\end{array}$ & $\begin{array}{r}40[55.3 \%] \\
35[45.3 \%] \\
01[1.3 \%]\end{array}$ \\
\hline $\begin{array}{l}\text { 8. Alternative choice of interest other than dentistry } \\
\text { Medicine } \\
\text { Engineering } \\
\text { Others }\end{array}$ & $\begin{array}{r}10[66.6 \%] \\
01[6.6 \%] \\
04[26.6 \%]\end{array}$ & $\begin{array}{r}41[68.3 \%] \\
07[11.6 \%] \\
12[20 \%]\end{array}$ & $\begin{array}{r}51[68 \%] \\
08[10.7 \%] \\
16[21.3 \%]\end{array}$ \\
\hline $\begin{array}{l}\text { 9. After completing BDS do you like to } \\
\text { Do post-graduation } \\
\text { Clinical practice } \\
\text { Others }\end{array}$ & $\begin{array}{r}10[66.6 \%] \\
04[26.6 \%] \\
01[6.6 \%]\end{array}$ & $\begin{array}{r}38[63.3 \%] \\
15[25 \%] \\
07[11.6 \%]\end{array}$ & $\begin{array}{r}48[64 \%] \\
19[25.3 \%] \\
08[10.7 \%]\end{array}$ \\
\hline $\begin{array}{l}\text { 10. Are you happy with your decision } \\
\text { in choosing dentistry } \\
\text { Yes } \\
\text { No }\end{array}$ & $\begin{array}{l}11[73.3 \%] \\
04[26.6 \%]\end{array}$ & $\begin{array}{l}47[78.3 \%] \\
13[21.6 \%]\end{array}$ & $\begin{array}{l}58[77.3 \%] \\
17[22.7 \%]\end{array}$ \\
\hline
\end{tabular}

et al in which the $51 \%$ of the students felt that dental treatment helps to serve the people and it enhances the standard of living. ${ }^{16}$ This finding shows disparity with the study conducted by Umesh et al, on Indian students where $(85.3 \%)$ most of the students felt that dentistry would help them to be financially stable and only a few felt that dentistry as a profession can help people. ${ }^{17}$ As stated by the present study medicine was the $1^{\text {st }}$ priority for most of the students and they choose dentistry with lack of interest. The reason behind this was according to the study coordinated by Parsa et al, most of the participants felt that medicine as an high-brow testing profession which provides the chance to save lives, highly respectable job, availability of job vacancy, expected earnings, and to look after the public health. ${ }^{18}$ An appropriate reason for choosing dentistry as a second fiddle by the students, this was due to lack of job vacancy and not competent enough to start their own clinical practice in the dental 
field because maximum number of experienced dentists are available in this field so the fresher's are not getting an opportunity to expose their hand skills, as reported in the study conducted by Brand at al. ${ }^{14}$ Eighty percent of the students participating in the present study were females, this was similar to the other studies conducted by Rashmi et al' Nupur et al. ${ }^{19,20}$ In the present study the participants have chosen dentistry because of their family impact, this finding was similar to the study conducted by Marino et al Nadya et al, Halawany et al have disclosed a robust family influence on their career decisions..$^{21-23}$ This finding shows variation in the study conducted by Skelly et al, Tom et al, Khami et al, where majority of the students have chose dentistry by choice as a professional career because of their own interests in science and research, use of personal or manual skills, financial rewards, security and higher social hierarchy, ${ }^{24,25,26}$ and Farid et al conducted a study in which the parental influence was considered to be very sparse and this also varies with present study. ${ }^{27}$ Majority of the students in the present study have chosen dentistry as a optional career, due to family impact, unable to procure a admission in medical course, this findings shows disparity to the study conducted by Crossley et al, where most of the students chose dentistry for professional status, job security and financially profitable. ${ }^{28}$ In the current study the overall population was only 75 students and this population was less when compared to other studies. Most of the students were the first graduate from their family and they have lack of ideas about choosing their tertiary education and majority of them were from rural sectors. More studies with higher sample size and strong sampling model are needed to conclude this result.

\section{Conclusion}

The present study concludes that majority of the first year dental students choose dentistry as their career chance because as they were unable to get an admission in medical course so they choose dentistry as their second chance priority, some of them choose this branch due to their family impact. Most of the participants in the current study were females. Majority of them in the study were willing to do post graduation in the field of dentistry. In the present study most of the students have lack of awareness about the field of dentistry so they felt that the field of medicine is superior in status when compared to dentistry, therefore in order to overcome these types of thoughts from the students mind, our government should establish an teaching methodology which is compulsory where in after their secondary education, the aptitude of the students should be identified and students who are willing to go for dental and medical fields should be encouraged.

\section{Acknowledgements}

I would like to express deep gratitude to R. Jothi basu and J. Nirmala for their encouragement and support throughout the course of my work.

I would like to thank all my friends for their help in the whole process leading to the conceptualization of the project.

\section{References}

1. AnbuSelvan GJ, Gokulnathan S, PrabuRajan V, RajaRaman G, Kumar SS, Thangavelu A. A study among dental students regarding the factors influenced dental students to choose dentistry as career. J Pharm Bioallied Sci 2013;5(Suppl 1):S36-S38.

2. Al-Bitar ZB, sonbol HN, AL-Omari LK. Reasons for choosing dentistry as a career by Arab dental students. Eur J Dent Educ 2008;12:247-51.

3. Patel D, Saiyed MH. Reasons for choosing dentistry as a career: A study of first year dental students, India. J Int Oral Health 2009;1:10-9.

4. Rupp JK, Jones DL, Seale NS. Dental students' knowledge about careers in academic dentistry. J Dent Educ 2006; 70:1051-60.

5. Amith HV, D’Cruz AM, Jasil M, Mansor MM, Antony NA, Devi NG, et al. Career in dentistry: By choice or chance reasons for choosing dentistry among the first-year dental students of a college in India. J Orofac Sci 2013;5:114-7.

6. Glossary of Dental Clinical and Administrative terms. American Dental Association. Retrieved 2014 February.

7. Nagesh L, Gunjal S. Attitudinal changes related to profession among dental students during their professional education. JAADR 2011;2(2):21-26.

8. Hallisey J, Hanningan A, Ray N. Reasons for choosing dentistry as a career - A survey of dental students attending a dental school in Ireland during 1998-99. Eur J Dent Edu 2000; 4:77-81.

9. Bernable E, Icaza JL, Delgado-Angulo EK. Reasons for choosing dentistry as a career: A study involving male and female first-year dental students in peru. Eur J Dent Edu2006; 10:236-41.

10. Jaiswal AK, Pachava S, Sanikommu S. "Why dentistry? A cross-sectional study of budding dentists in Andhra Pradesh". IJSS.2014;1(6):17-21.

11. Lawson WR. The choice of dentistry as a career. N Z Dent J 1976;72:155-8.

12. Aguiar CM, Pessoa MA, Camara AC, Perrier RA, de Figueiredo JA. Factors involved in the choice of dentistry as an occupation by pernambuco dental students in Brazil. J Dent Educ 2009;73: 1401-7. 
13. Du Toit J, et al. Dental students motivations for their career choice: an international investigative reports. J Dent Educ.2014;78(4):605-13.

14. Brand AA, Chikte UM, Thomas CJ. Choosing dentistry as a career-A profile of entering students (1992) to the university of Sydney, Australia. Aust Dent J 1996;41:198-205.

15. Sofola OO, Uti OG, Akpene OI. Does exposure to dental education change the perceptions of Nigerian students to dentistry as a profession? Eur J Dent Educ 2008;12:159-62.

16. Singh A, Saxena S, Tiwari V, Tiwari U, Vishnu V. First-year dental students motivation for choosing the dental profession: A questionnaire study of budding dentists in Central India. Int $\mathrm{J}$ Educ Psychol Res 2015;1:272-7.

17. Umesh K, Chavan S, Singh S. Dentistry by choice or chance. J Indian Assoc Public Health Dent 2011;17 (Supp II) :662-5.

18. Parsa S, et al. Freshmen versus interns speciality interests. Arch Iran Med 2010;13(6):509-15.

19. Rashmi M, Virjee K, Yadava TS, Vijayakumar N, Shoba M. Dentistry as a career: Motives and perception of dental students attending Dental Colleges in Bengaluru city, Karnataka, India. J Indian Assoc Public Health Dent 2014;12:194-8.

20. Sharma N, Kabasi S, Pati AR. Perception of 1st year dental students studying in Odisha toward career choice: A cross-sectional survey. J Indian Assoc Public Health Dent 2015;13:499-53.
21. Marino RJ, Morgan MV, Winning T, Thomson WM, Marshall RJ, Gotjamanos T, et al. Sociodemographic backgrounds and career decisions of Australian and New Zealand dental students. J Dent Edu 2006;70(2):169-78.

22. Avramova N, et al. First year dental students motivation and attitudes for choosing the dental profession. Acta Med Acad.2014;43(2):113-121.

23. Halawany HS. Career motivations, perceptions of the future of dentistry and preferred dental speacialities among Saudi dental students. Open Dent J 2014;8:129-135.

24. Skelly AM, Flemming GJ. Perceptions of a dental career among successful applicants for dentistry compared with those of fifth year dental students. Prim Dent care 2002;9:41-6.

25. Tom K, et al. Reasons for choosing dentistry as a career-Survey of dental students in AIMST University. Malasiyan J Dent 2014,Vol.36 Issue 1, p1-4.4p.

26. Khami MR, Muratomaa H, Jafarian M,Vehkalahti MM, Virtanen JI. Study motives and career choice of Iranian dental students. Med Princ Pract 2008;17(3):221-6.

27. Bourzgui $\mathrm{F}$, et al. Motivational factors influencing career choices of Moroccan dental students. Oral Health Dent Manag. 2014;13(2):390-4.

28. Crossley ML, Mubarik A. A comparative investigation of dental and medical students' motivation towards career choice. Br Dent J 2002;193:471-3.

\section{Address of Correspondence}

R.J. Shobana priya,

(CRRI)

Ultra's Best Dental Science College.

Email id: shobykiddy@gmail.com

Phone no: 9952184648

\section{Authors \\ '(CRRI) ultra's best dental science college}

${ }^{2}$ Senior lecturer in public health dentistry in ultra's best dental science college

${ }^{3}$ Reader in public health dentistry in ultra's best dental science college

${ }^{4}$ Principal of the ultra's best dental science college,

${ }^{5}$ II year PG in public he alth dentistry in ultra's best dental science college

${ }^{6} \mathrm{Head}$ of the Department in Public health dentistry in ultra's best dental science college

How to cite this article : R.J. Shobana Priya, R. Palanivel Pandian, Sangeeta Chavan, K.S. Premkumar, S. Shrimathi, K. Umesh. Dentistry by Volition or By Happenstance - A Questionnaire Study. Journal of Scientific Dentistry 2018;8(1):2-6

Source of support : Nil, Conflicts of Interest : None declared 